\title{
A Simplified Model of Reactant Adsorption in Normal Pulse Voltammetry
}

\author{
Šebojka Komorsky-Lovrić, Milivoj Lovrić*
}

Divkovićeva 13, HR-10090 Zagreb, Croatia
* Corresponding author's e-mail address: mlovric@irb.hr

RECEIVED: November 23, 2018 * REVISED: January 21, 2019 * ACCEPTED: January 23, 2019

\begin{abstract}
Normal pulse voltammetry and chronoamperometry of reversible electro-oxidation complicated by the reactant adsorption on the surface of stationary, planar electrode is investigated theoretically. A simple model of chronoamperometry is compared with a rigorous model of voltammetry. The solution of former is analytical, but it applies to the linear isotherm. However, it explains the origin of maximum of the current-potential curves and its relationship with the pulse duration. The second model is based on digital simulation and describes voltammograms that correspond to the Langmuir isotherm. The accumulation of the reactant during the potential scan is calculated. The limits of electroanalytical application of the normal pulse voltammetry are determined.
\end{abstract}

Keywords: reactant adsorption, normal pulse voltammetry, chronoamperometry, theory.

\section{INTRODUCTION}

A difference between normal pulse polarography (NPP) and normal pulse voltammetry (NPV) is in the life time of mercury drop electrode. In NPP a single pulse is applied to each drop, while in NPV a series of pulses is applied to a single drop. ${ }^{[1-6]}$ In fact, NPV can be performed with solid electrodes. Under this condition the response of reversible electrode reaction depends on the duration of the period between pulses. During this period the reactant is regenerated and the response resembles polarographic wave. ${ }^{[3,5]}$

In NPP the contamination of electrode surface by products is minimized because the electrolysis time is restricted to short pulse duration. However, the method is highly sensitive to the reactant adsorption. ${ }^{[7-11]}$ Under its influence the response exhibits maximum and diminished limiting current. ${ }^{[12-18]}$ The effect was used for the investigation of anion induced adsorption of metal ions. ${ }^{[19-24]}$ The same type of response was observed in the normal pulse voltammetry. ${ }^{[25,26]}$ In this paper it is demonstrated that the maximum can be qualitatively explained by the theory of single pulse chronoamperometry.

\section{MODEL}

A reversible electrode reaction complicated by the reactant adsorption is considered:

$$
\mathrm{A}_{\mathrm{ads}} \rightleftharpoons \mathrm{A} \rightleftharpoons \mathrm{B}^{n+}+n \mathrm{e}^{-}
$$

On the stationary, planar electrode in non-stirred solution the mass transport is described by the following differential equations and the initial and boundary conditions:

$$
\begin{aligned}
& \partial c_{A} / \partial t=D \partial^{2} c_{A} / \partial x^{2} \\
& \partial c_{B} / \partial t=D \partial^{2} c_{B} / \partial x^{2} \\
& t>0, x \geq 0: c_{A}=c_{A}^{*}, c_{B}=0, \Gamma_{A}=0 \\
& t>0, x \rightarrow \infty: c_{A} \rightarrow c_{A}^{*}, c_{B} \rightarrow 0 \\
& x=0: c_{B, x=0}=c_{A, x=0} \exp (\varphi) \\
& \varphi=(n F / R T)\left(E-E^{0}\right)
\end{aligned}
$$

(a) BY This work is licensed under a Creative Commons Attribution 4.0 International License. 


$$
\begin{aligned}
& \beta c_{\mathrm{A}, x=0}=\Gamma_{\mathrm{A}} /\left(\Gamma_{\mathrm{S}}-\Gamma_{\mathrm{A}}\right) \\
& D\left(\partial c_{\mathrm{A}} / \partial x\right)_{x=0}=1 / n F S+\mathrm{d} \Gamma_{\mathrm{A}} / \mathrm{d} t \\
& D\left(\partial c_{\mathrm{B}} / \partial x\right)_{x=0}=-1 / n F S
\end{aligned}
$$

The meanings of all symbols are reported in Table 1. The standard conditions are $298.15 \mathrm{~K}$ and $101325 \mathrm{~Pa}$. Equations (2) and (3) are transformed by the substitution $\psi=A+B$ :

$$
\partial c_{\psi} / \partial t=D \partial^{2} c_{\psi} / \partial x^{2}
$$

\begin{tabular}{|c|c|}
\hline Symbol & Meaning \\
\hline$C_{A}, C_{B}$ & concentrations of the reactant and product \\
\hline$c_{\psi}$ & sum of concentrations of the reactant and product \\
\hline$c_{A}^{*}$ & concentration of the reactant in the bulk of solution \\
\hline D & diffusion coefficient \\
\hline $\mathrm{d} E$ & potential increment \\
\hline E & electrode potential \\
\hline$E_{0}$ & standard potential of electrode reaction \\
\hline$E_{\mathrm{p}}$ & peak potential \\
\hline$E_{\text {st }}$ & starting potential \\
\hline$F$ & Faraday constant \\
\hline 1 & current \\
\hline$n$ & number of electrons \\
\hline$R$ & gas constant \\
\hline$S$ & electrode surface area \\
\hline$t$ & time \\
\hline$t_{\text {acc }}$ & accumulation time \\
\hline$t_{\mathrm{p}}$ & pulse duration \\
\hline$t_{1}$ & duration of the period between pulses \\
\hline$T$ & temperature \\
\hline$x$ & distance perpendicular to the electrode surface \\
\hline$\beta$ & adsorption constant \\
\hline$\Gamma_{\mathrm{A}}$ & surface concentration of adsorbed reactant \\
\hline$\Gamma_{\mathrm{s}}$ & $\begin{array}{c}\text { maximum surface concentration of adsorbed } \\
\text { reactant }\end{array}$ \\
\hline$\Delta t$ & time increment \\
\hline$\Delta x$ & space increment \\
\hline$\Phi$ & dimensionless current \\
\hline$\theta_{\mathrm{A}}$ & surface coverage by the adsorbed reactant \\
\hline$\varphi$ & dimensionless potential \\
\hline
\end{tabular}

Table 1. Meanings of symbols.

$$
\begin{aligned}
& t=0, x \geq 0: c_{\psi}=c_{\mathrm{A}}^{*}, \Gamma_{\mathrm{A}}=0 \\
& t>0, x \rightarrow 0: c_{\Psi}=c_{\mathrm{A}}^{*} \\
& x=0: D\left(\partial c_{\psi} / \partial x\right)_{x=0}=\mathrm{d} r_{\mathrm{A}} / \mathrm{d} t \\
& c_{\Psi, x=0}=c_{\mathrm{A}, x=0}[1+\exp (\varphi)] \\
& c_{\mathrm{B}, x=0}=c_{\Psi, x=0} \exp (\varphi)[1+\exp (\varphi)]^{-1}
\end{aligned}
$$

Equations (11) and (3) are solved by the finite difference method. ${ }^{[27]}$ The time increment and the dimensionless diffusion coefficient are defined as follows: $\Delta t=t_{\mathrm{p}} / 50$ and $D \Delta t \Delta x^{-2}=\mathrm{dd}$. The surface coverage $\theta_{\mathrm{A}}=\Gamma_{\mathrm{A}} / \Gamma_{\mathrm{s}}$ is solved by the combination of equations (14), (15) and (8):

$$
\begin{aligned}
& \left(\theta_{\mathrm{A}, t+\Delta t}\right)^{2}-\mathrm{B} \theta_{\mathrm{A}, t+\Delta t}+\mathrm{C}=0 \\
& \mathrm{~B}=1+\left(c_{\mathrm{A}}^{*} / \Gamma_{\mathrm{S}}\right)\left(D t_{\mathrm{p}}\right)^{1 / 2}(\mathrm{dd} / 50)^{1 / 2} c_{\psi, \Delta x}+ \\
& +\theta_{\mathrm{A}, t}+[1+\exp (\varphi)]\left(\left(D t_{\mathrm{p}}\right)^{1 / 2} / \beta \Gamma_{\mathrm{S}}\right)(\mathrm{dd} / 50)^{1 / 2} \\
& \mathrm{C}=\left(c_{\mathrm{A}}^{*} / \Gamma_{\mathrm{S}}\right)\left(D t_{\mathrm{p}}\right)^{1 / 2}(\mathrm{dd} / 50)^{1 / 2} c_{\psi, \Delta x}+\theta_{\mathrm{A}, t}
\end{aligned}
$$

The current was solved by equation (10). A dimensionless current $\Phi=I\left(\pi t_{\mathrm{p}} / D\right)^{1 / 2}\left(n F S c_{\mathrm{A}}{ }^{*}\right)^{-1}$ is reported as a function of the pulse potential.

\section{Analytical Approximation}

Electrode reaction (1) is considered under the single pulse chronoamperometric conditions on stationary, planar electrode. It is assumed that initially the electrode surface is covered by the adsorbed reactant and that the adsorbate is in the equilibrium with the bulk concentration of the reactant and that the adsorption satisfies linear isotherm. So, differential equations (2) and (3) have to be solved under the following initial conditions:

$$
t=0, x \geq 0: c_{\mathrm{A}}=c_{\mathrm{A}}^{*}, c_{\mathrm{B}}=0, \Gamma_{\mathrm{A}, \text { ini }}=\Gamma_{\mathrm{S}} \beta c_{\mathrm{A}}^{*}
$$

The boundary conditions (5)-(7) and (9) and (10) apply, but the condition (8) is replaced by the following one:

$$
\Gamma_{\mathrm{A}}=\Gamma_{\mathrm{S}} \beta c_{\mathrm{A}, x=0}
$$

During the pulse the potential is constant and the solution can be obtained by Laplace transforms. 


$$
\begin{aligned}
& \Phi=\exp (\varphi)\left[1-\exp (\varphi) Z\left(a t_{p}^{1 / 2}\right) /(1+\exp (\varphi))\right] \\
& Z\left(a t_{p}^{1 / 2}\right)=a\left(\pi t_{p}\right)^{1 / 2} \exp \left(a^{2} t_{p}\right) \operatorname{erfc}\left(a t_{p}^{1 / 2}\right) \\
& a=D^{1 / 2}(1+\exp (\varphi)) / \Gamma_{s} \beta
\end{aligned}
$$

\section{RESULTS AND DISCUSSION}

Normal pulse voltammogram that is influenced by the reactant adsorption exhibits a maximum and diminished limiting current, as can be seen in Figures 1 and 2 . The form of response depends on the ratio of the reactant bulk concentration and the maximum surface concentration of adsorbate $\left(c_{\mathrm{A}}{ }^{*} / \Gamma_{\mathrm{S}}\right)$ and on the product of the latter and the adsorption constant $\left(\beta \Gamma_{\mathrm{s}}\right)$. Figure 1 shows that the maximum dimensionless peak current decreases from 2.70 to 1.06 if the ratio $c_{A}{ }^{*} / \Gamma_{\mathrm{S}}$ increases from 100 to $1000 \mathrm{~cm}^{-1}$. This means that the relationship between real peak current and the reactant concentration is not linear. The limiting current increases with the increasing ratio $c_{A}{ }^{*} / \Gamma_{S}$ because of the development of main wave in front of the adsorptive post wave. These two parts of the response are well separated in curve 5 in Figure 1. The main wave originates

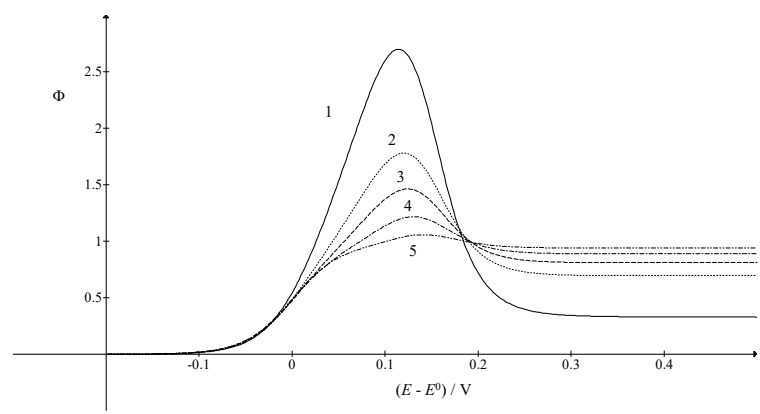

Figure 1. Dimensionless normal pulse voltammograms influenced by the reactant adsorption. $D=10^{-5} \mathrm{~cm}^{2} \mathrm{~s}^{-1}, t_{\mathrm{p}}=$ $0.050 \mathrm{~s}, t_{1}=0.950 \mathrm{~s}, d E=2 \mathrm{mV}, \beta \Gamma_{\mathrm{s}}=0.1 \mathrm{~cm}$ and $\left(c_{\mathrm{A}}^{*} / \Gamma_{\mathrm{s}}\right) /$ $\mathrm{cm}^{-1}=100$ (1), 200 (2), 300 (3), 500 (4) and 1000 (5).

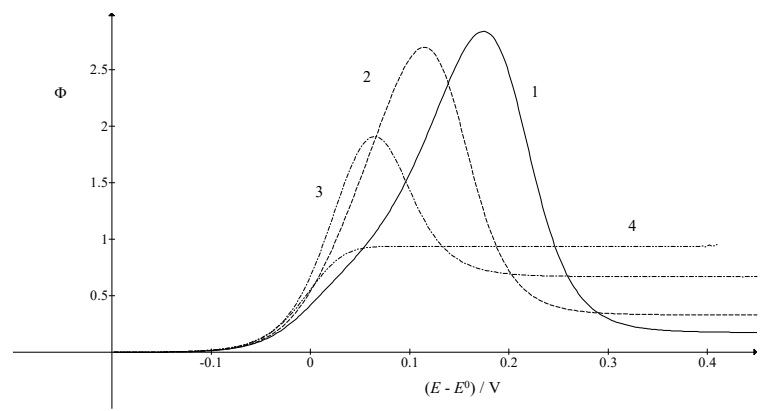

Figure 2. Reactant adsorption influenced NPV; $c_{\mathrm{A}}{ }^{*} / \Gamma_{\mathrm{S}}=$ $100 \mathrm{~cm}^{-1}$ and $\beta \Gamma_{\mathrm{s}} / \mathrm{cm}=1$ (1), 0.1 (2), 0.01 (3) and 0.001 (4). All other data are as in Figure 1. from the oxidation of dissolved reactant on the electrode surface that is covered by the adsorbate.

The difference between half-wave potential of the main wave and the peak potential of post wave depends on the product $\beta \Gamma_{\mathrm{s}}$. This is shown in Figure 2. If $\beta \Gamma_{\mathrm{s}}=1 \mathrm{~cm}$ the peak potential is $0.174 \mathrm{~V} v s$. $E^{0}$, but decreases to $0.114 \mathrm{~V}$ for $\beta \Gamma_{\mathrm{s}}=0.1 \mathrm{~cm}$ and to $0.064 \mathrm{~V}$ for $\beta \Gamma_{\mathrm{s}}=0.01 \mathrm{~cm}$. The maximum vanishes if $\beta \Gamma_{\mathrm{s}}=0.001 \mathrm{~cm}$. Also, the limiting current increases as the adsorption becomes weaker.

For analytical purpose it is necessary that the amperometric constant $\Phi_{\mathrm{p}}$ does not depend on reactant concentration. Figure $3 \mathrm{~A}$ shows that this is satisfied if the ratio $c_{A} * / \Gamma_{s}$ is smaller than $1 \mathrm{~cm}^{-1}$. The dimensionless peak current is equal to 9.43 if $\log \left(c_{A}^{*} / \Gamma_{\mathrm{s}}\right)=-3$ and does not decrease more than $1 \%$ if $\log \left(c_{A}^{*} / \Gamma_{\mathrm{s}}\right)<0$. If one assumes that $\Gamma_{\mathrm{s}}=10^{-9} \mathrm{~mol} \mathrm{~cm}{ }^{-2}$ and $\beta=10^{8} \mathrm{~cm}^{3} \mathrm{~mol}^{-1}$, the NPV with $t_{1}=0.95 \mathrm{~s}$ and $t_{\mathrm{p}}=0.05 \mathrm{~s}$ can be used for the electroanalysis of surface active compounds in concentrations lower than $10^{-6} \mathrm{~mol} \mathrm{~L}^{-1}$. Figure $3 \mathrm{~B}$ shows that peak potentials are equal to $0.118 \mathrm{~V}$ vs. $E^{0}$ if $\log \left(c_{\mathrm{A}}{ }^{*} / \Gamma_{\mathrm{S}}\right)<0$ and decreases to $0.110 \mathrm{~V}$ vs. $E^{0}$ if $c_{A}{ }^{*} / \Gamma_{S}=40 \mathrm{~cm}^{-1}$. At higher values of this ratio the peak potential increases to $0.136 \mathrm{~V} v s$. $E^{0}$. This can be also seen in Figure 1. The dimensionless limiting current is equal to 0.11 if $c_{\mathrm{A}} * / \Gamma_{\mathrm{s}}<10 \mathrm{~cm}^{-1}$.

The presented current-potential relationships are consequences of surface concentrations of adsorbate. They are shown in Figure 4 . The points represent the values of $\theta_{\mathrm{A}}$ at the end of each period between pulses. During the experiment the electrode is charged to $-0.2 \mathrm{~V} v$ s. $E^{0}$ in

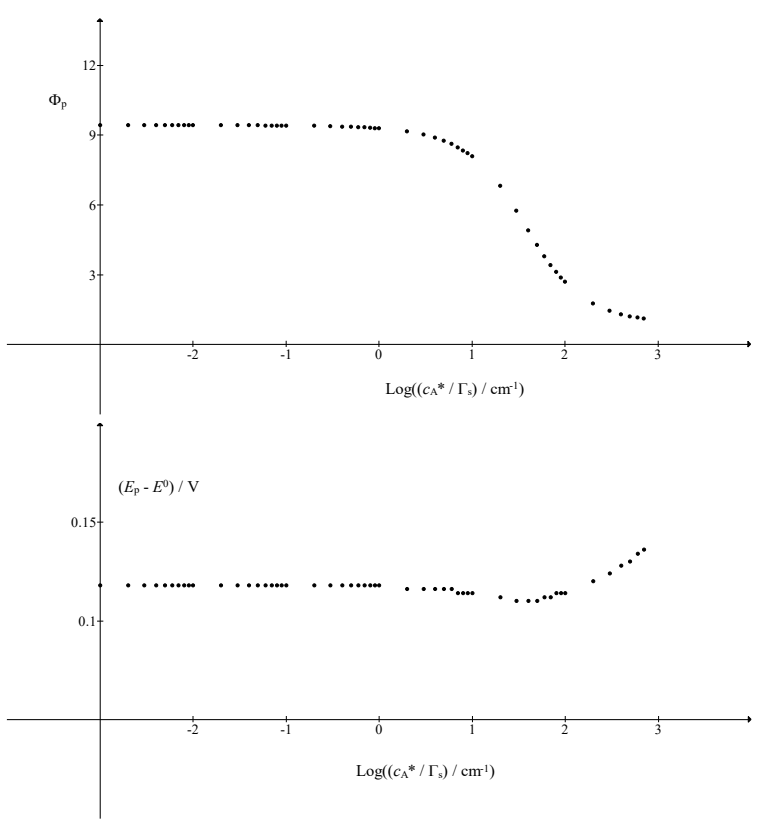

Figure 3. Dependence of dimensionless peak current (A) and peak potentials (B) of NPV on the logarithm of the ratio $C_{A} * / \Gamma_{\text {s. }}$. All other data are as in Figure 1. 
between pulses and to higher potentials on the pulses. Each pulse is $2 \mathrm{mV}$ higher than the previous one. So, it takes 50 seconds to scan $100 \mathrm{mV}$. In Figure 4 the time $100 \mathrm{~s}$ corresponds to $E_{\text {pulse }}=E^{0}$ and $150 \mathrm{~s}$ to $E_{\text {pulse }}-E^{0}=0.1 \mathrm{~V}$. The reactant is adsorbing during the period between pulses and during the pulse if $E_{\text {pulse }}-E^{0}<0.1 \mathrm{~V}$. If $c_{\mathrm{A}}{ }^{*} / \Gamma_{\mathrm{s}}=50 \mathrm{~cm}^{-1}$ the peak potential is $0.110 \mathrm{~V} v$ s. $E^{0}$ and $\theta_{\mathrm{A}}$ increases to 0.772 after $100 \mathrm{~s}$, but decreases to 0.473 before the last pulse. This is because a certain amount of adsorbate is oxidized on the pulse, but partly restored after the pulse. If $c_{\mathrm{A}}{ }^{*} / \Gamma_{\mathrm{S}}=$ $1 \mathrm{~cm}^{-1}$ the highest surface coverage is 0.029 and this shows that the highest dimensionless peak current and the lowest limiting current appear under the conditions of linear isotherm. The main wave dominates the response if the coverage is 0.99 regardless of peak potentials.

Figure 5 shows concentration profiles of reactant and product at the end of period after the pulse to $0.398 \mathrm{~V}$ vs. $E^{0}$ and before the pulse to $0.400 \mathrm{~V}$. In this period the product created at $0.398 \mathrm{~V}$ is reduced back to the adsorbed and dissolved reactant. In this figure $\theta_{\mathrm{A}}=0.817$ and $c_{\mathrm{A}, \mathrm{x}=0}=$ $0.4465 c_{A}^{*}$. This surface coverage is smaller than the maximum one because the product diffuses towards both the electrode surface and the bulk of solution. Also, the reactant is diffusing towards the minimum concentration. However, the accumulation of reactant at the electrode surface occurs in each period between pulses until the end of scan and this process is the reason for the development of deep diffusion layer of reactant that is shown in Figure 5 . In this simulation the space increment is $1.58 \times 10^{-4} \mathrm{~cm}$ and 500 increments correspond to $0.79 \mathrm{~mm}$. A theoretical diffusion layer thickness after the accumulation of 300 seconds and $D=10^{-5} \mathrm{~cm}^{2} \mathrm{~s}^{-1}$ is $0.97 \mathrm{~mm}$, which is close to our result. ${ }^{28]}$ This layer causes the diminished limiting current. ${ }^{[17]}$

Figure 6 shows current-potential curves calculated by [Eq. (22)]. They are characterized by the maximum and the limiting value that is equal to 1 . The maximum is

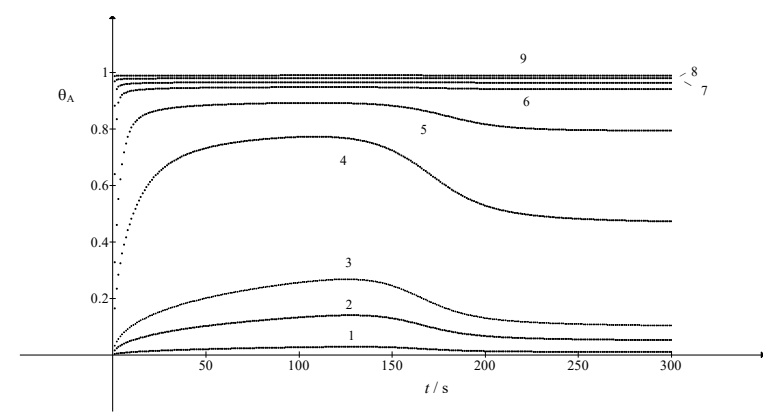

Figure 4. Dependence of surface coverage in NPV on the time. The values of $\theta_{A}$ at the end of each period between pulses are presented; $\left(c_{A}^{*} / \Gamma_{\mathrm{s}}\right) / \mathrm{cm}^{-1}=1(1), 5(2), 10$ (3), 50 (4), 100 (5), 200 (6), 300 (7), 500 (8) and 1000 (9). All other data are as in Figure 1. defined by the equation: $\left(D t_{\mathrm{p}}\right)^{1 / 2}\left(\beta \Gamma_{\mathrm{s}}\right)^{-1}\left[1+\exp \left(F\left(E_{\mathrm{p}}-E^{0}\right) /\right.\right.$ $R T]=0.85$. For the peak potentials higher than $0.1 \mathrm{~V} v s$. $E^{0}$, the exponential term in this equation is much bigger than 1. So, the peak potential is defined by the following equation:

$$
\begin{gathered}
E_{\mathrm{p}}-E^{0}=0.059 \log \left(\beta \Gamma_{\mathrm{s}}\right)-0.0295 \log t_{\mathrm{p}}- \\
-0.0295 \log D+0.059 \log (0.85) \mathrm{V}
\end{gathered}
$$

These linear relationships are shown in Figures 7A and $8 \mathrm{~A}$. The straight lines marked as 1 in these figures satisfy the following equations: $E_{\mathrm{p}}-E^{0}=-0.030 \log t_{\mathrm{p}}+$ $0.084 \mathrm{~V}$ and $E_{\mathrm{p}}-E^{0}=0.060 \log \left(\beta \Gamma_{\mathrm{s}}\right)+0.181 \mathrm{~V}$.

Figures $7 \mathrm{~B}$ and $8 \mathrm{~B}$ show linear relationships between the logarithm of dimensionless peak current and the logarithms of pulse duration and the product $\beta \Gamma_{\mathrm{s}}$. They satisfy the equations $\log \Phi_{\mathrm{p}}=-0.5 \log t_{\mathrm{p}}+0.9$ and $\log \Phi_{\mathrm{p}}=\log \left(\beta \Gamma_{\mathrm{s}}\right)$ +2.14 . This means that dimensionless peak current is linearly proportional to the parameter $\beta \Gamma_{\mathrm{s}}\left(D t_{\mathrm{p}}\right)^{-1 / 2}$ if this parameter is bigger than 10 . Considering the initial condition (20), the real peak current depends on the surface concentration of adsorbed reactant: $I_{\mathrm{p}}=k \pi^{-1 / 2} n F S \Gamma_{\mathrm{A} \text {, ini }} \mathrm{t}_{\mathrm{p}}{ }^{-1}$. Also,

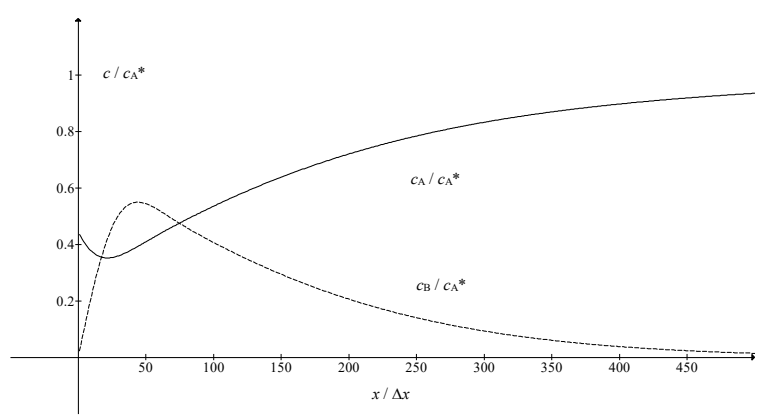

Figure 5. Concentration profiles of reactant and product at $-0.200 \mathrm{~V}$ vs. $E^{0}$ just before the pulse to $0.400 \mathrm{~V} ; c_{\mathrm{A}} * / \Gamma_{\mathrm{s}}=$ $100 \mathrm{~cm}^{-1}$. All other data are as in Figure 1.

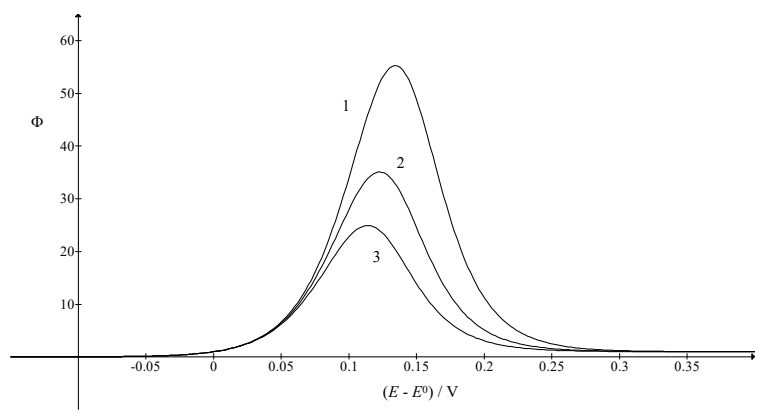

Figure 6. Chronoamperometry influenced by the reactant adsorption [Eq. 22]. $D=10^{-5} \mathrm{~cm}^{2} \mathrm{~s}^{-1}, \beta \Gamma_{\mathrm{s}}=0.1 \mathrm{~cm}$ and $t_{\mathrm{p}} / \mathrm{s}$ $=0.020$ (1), 0.050 (2) and 0.100 (3). 
the current is inversely proportional to the pulse duration. These are characteristics of surface electrode reactions. ${ }^{[28]}$ At very high potential the function $Z\left(a t_{p}^{1 / 2}\right)$, defined by [Eq. (23)], tends to 1 and the [Eq. (22)] is reduced to the form $\Phi=\exp (\varphi) /(1+\exp (\varphi))$. Obviously, $\lim _{\varphi \rightarrow \infty} \Phi=1$ and the real limiting current corresponds to the diffusion controlled oxidation of dissolved reactant: $\lim _{\text {lim }}=n F \mathrm{nC}_{\mathrm{A}}{ }^{*}\left(D / \pi \mathrm{t}_{\mathrm{p}}\right)^{1 / 2}$.

Figure 9 shows normal pulse voltammograms calculated for the linear isotherm. Comparing to Figure 6, one can observe the qualitative resemblance, but quantitative difference. Both peak currents and limiting currents are smaller in Figure 9 than in Figure 6. However, the relationships between peak potentials and the logarithms of pulse duration and the product $\beta \Gamma_{\mathrm{s}}$ are similar to the corresponding relationships in chronoamperometry. The straight lines marked as 2 in Figures $7 \mathrm{~A}$ and $8 \mathrm{~A}$ are defined by the equations: $E_{\mathrm{p}}-E^{0}=-0.036 \log t_{\mathrm{p}}+0.071 \vee$ and $E_{\mathrm{p}}-E^{0}=$ $0.058 \log \left(\beta \Gamma_{\mathrm{s}}\right)+0.176 \mathrm{~V}$, respectively. The logarithm of dimensionless peak current depends linearly on the logarithm of pulse duration $\left(\log \Phi_{\mathrm{p}}=-0.64 \log t_{\mathrm{p}}+0.127\right.$, see curve 2 in Figure 7B), but not on the logarithm of the product $\beta \Gamma_{\mathrm{s}}$. The later is shown in Figure $8 \mathrm{~B}$. In this figure the curve 2 tends to the asymptote $\log \Phi_{\mathrm{p}}=0.66 \log \left(\beta \Gamma_{\mathrm{s}}\right)+$ 1.82 , if $\log \left(\beta \Gamma_{\mathrm{s}}\right)<-1.5$, and to the maximum $\log \Phi_{\mathrm{p}}=1.114$ if $\beta \Gamma_{\mathrm{s}}=1$. This relationship can be also observed in Figure 2 , which means that it is not exclusive for the linear
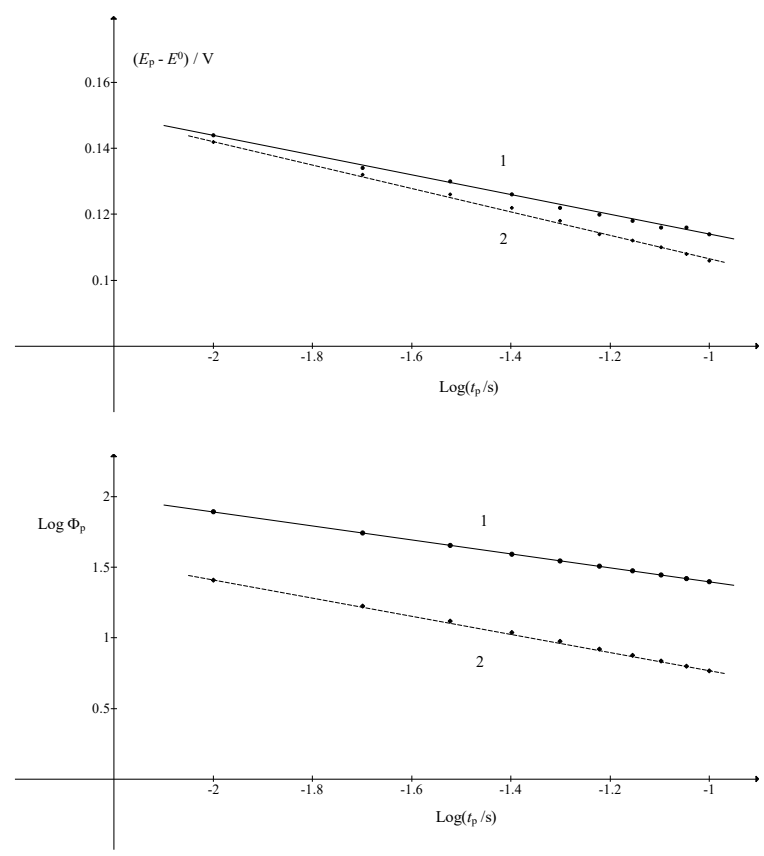

Figure 7. Dependence of peak potentials $(A)$ and the logarithm of dimensionless peak current (B) on the logarithm of pulse duration. Chronoamperometry (1) and normal pulse voltammetry (2). All data are as in Figure 6 and Figure 9. isotherm. It can be explained by the adsorption that is controlled by the diffusion.

The influence of the accumulation of reactant at the electrode surface on the normal pulse voltammograms is shown in Figure 10. The variation of the duration of adsorptive accumulation is achieved by changing the period between the pulses. Considering Figure 4, an approximate equation for the accumulation time is $t_{\mathrm{acc}}=\left(E_{\mathrm{p}}-E_{\mathrm{st}}\right)\left(t_{1}+t_{\mathrm{p}}\right)$ / $d E$. The adsorption of electro-inactive substance on the stationary, planar electrode from unstirred electrolyte is defined by the following equation. ${ }^{[8,29]} \Gamma=c^{*} \beta \Gamma_{\mathrm{s}}[1-$ $\left.\exp \left(D t_{\mathrm{acc}} \beta^{-2} \Gamma_{\mathrm{s}}^{-2}\right) \operatorname{erfc}\left(\left(D t_{\mathrm{acc}}\right)^{1 / 2} / \beta \Gamma_{\mathrm{s}}\right)\right]$. The relationship
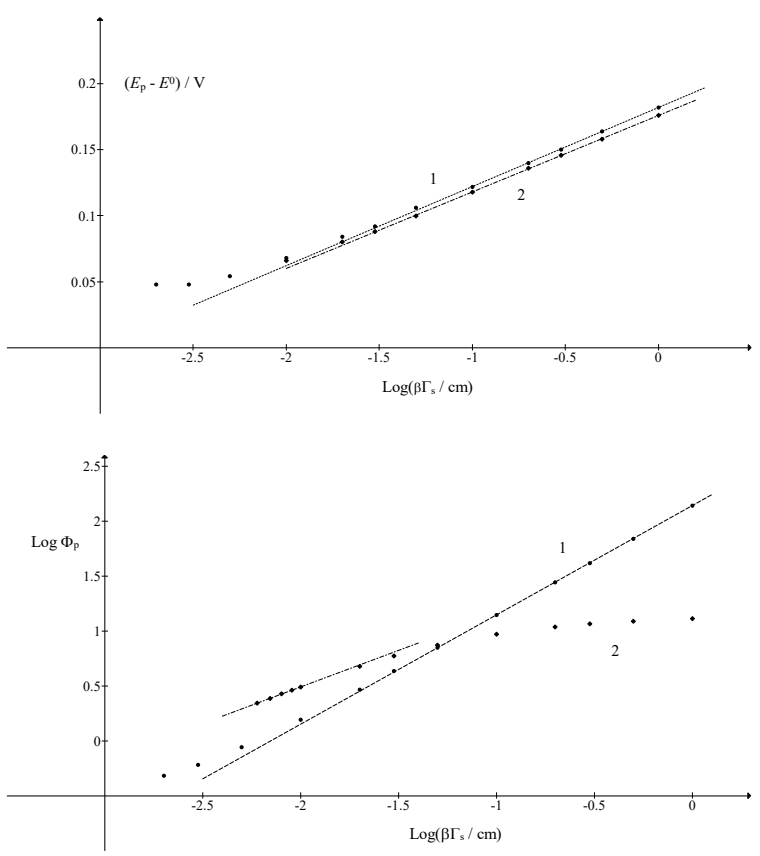

Figure 8. Dependence of peak potentials (A) and the logarithm of dimensionless peak current (B) on the logarithm of the product $\beta \Gamma_{\mathrm{s}}$. Chronoamperometry (1) and normal pulse voltammetry (2); $t_{\mathrm{p}}=0.050 \mathrm{~s}$ and all other data are as in Figure 6 and Figure 9.

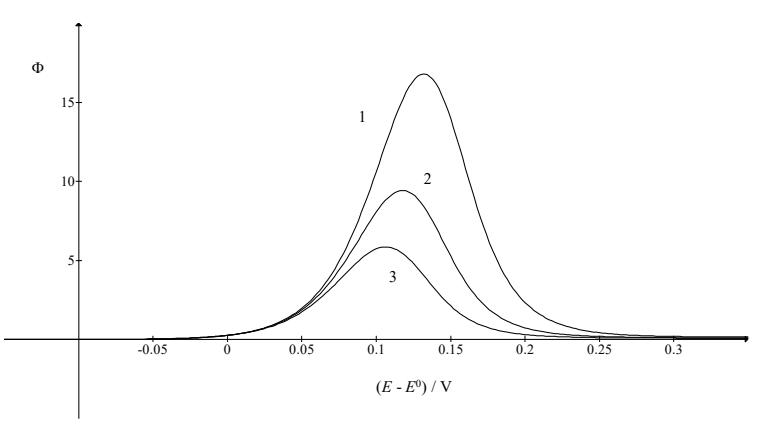

Figure 9. Dependence of normal pulse voltammograms on the pulse duration. $D=10^{-5} \mathrm{~cm}^{2} \mathrm{~s}^{-1}, c_{\mathrm{A}}^{*} / \Gamma_{\mathrm{s}}=0.01 \mathrm{~cm}^{-1}, \beta \Gamma_{\mathrm{s}}$ $=0.1 \mathrm{~cm}, t_{\mathrm{p}}+t_{1}=1 \mathrm{~s}, t_{\mathrm{p}} / \mathrm{s}=0.020$ (1), 0.050 (2) and 0.100 (3). 
between dimensionless peak currents, shown in Figure 10, and the function $1-\exp \left(D t_{\mathrm{acc}} \beta^{-2} \Gamma_{\mathrm{s}}^{-2}\right) \operatorname{erfc}\left(\left(D t_{\mathrm{acc}}\right)^{1 / 2} / \beta \Gamma_{\mathrm{s}}\right)$ is shown in Figure 11. The straight line in this figure shows that the peak current is linearly proportional to the amount of adsorbed reactant. This is the reason for the difference between straight lines 1 and 2 in Figure 7B. The accumulation time depends on the peak potential, which itself depends on the pulse duration time. Although the sum $t_{1}+t_{\mathrm{p}}$ may be constant, the variation of $t_{\mathrm{p}}$ between 0.010 and $0.100 \mathrm{~s}$ changes the accumulation time from 171 to $153 \mathrm{~s}$. So, the peak current is proportional to $t_{\mathrm{p}}-0.64$ because it is inversely proportional to the square root of $t_{\mathrm{p}}$ and additionally decreases with the decreasing accumulation time.

The data shown in Figure 10 were analysed by the log-log plot and an approximate relation $\Phi_{\mathrm{p}}=k t_{\mathrm{acc}}{ }^{0.55}$ was observed. So, under the conditions of linear isotherm, the real peak current is proportional to the bulk concentration of reactant and to the square root of accumulation time and inversely proportional to the pulse duration $\left(I_{\mathrm{p}} \sim\right.$ $\left.c_{\mathrm{A}} * t_{\mathrm{acc}}{ }^{0.55} t_{\mathrm{p}}{ }^{-1.14}\right)$.

Diminished limiting currents of normal pulse voltammograms can be explained by the theory of chronoamperometry if the initial conditions in [Eq. (20)] are changed. Considering Figure 5, the reactant concentration at the electrode surface during the period before the last pulse is much smaller than the bulk concentration. In the derivation of [Eq. (22)] one can neglect the dependence of reactant concentration on the space variable and state that for $t=0$ and $x \geq 0$ the initial concentration of reactant is a certain $c_{\mathrm{A} \text {,ini }}$ that is smaller than $c_{\mathrm{A}}{ }^{*}$ and that the initial surface concentration of adsorbed reactant is equal to the product $\beta \Gamma_{\mathrm{S}} c_{\mathrm{A}, \mathrm{ini}}$. Under this assumption the dimensionless current is defined by the modified [Eq. (22)] in which the right-hand side is multiplied by the ratio $c_{\mathrm{A}, \text { ini }} / c_{\mathrm{A}}{ }^{*}$. The resulting current-potential curves are shown in Figure 12 together with the corresponding normal pulse voltammogram. The later is characterized by $\Phi_{\mathrm{p}}=9.43$ and $\Phi_{\lim }=0.11$. If $c_{\mathrm{A}, \text { ini }} / c_{\mathrm{A}}{ }^{*}=$ 0.3 the maximum and the limiting currents in chronoamperometry are equal to 10.52 and 0.30 , respectively, and if $c_{\mathrm{A}, \text { ini }} / c_{\mathrm{A}}{ }^{*}=0.1$ these currents are 3.51 and 0.10 . These results show that in the normal pulse voltammetry both the maximum and the limiting currents depend on the deep diffusion layer that develops during the potential scan.

\section{CONCLUSIONS}

A chronoamperometric model proposed in this paper can explain the origin of maximum in normal pulse voltammetry that is influenced by the adsorption of reactant. It describes well the dependence of peak currents and potentials on the pulse duration. Also, it shows the influence of constant of adsorption on the peak potential under the condition of linear isotherm. However, it cannot predict quantitatively the peak current because it does not consider the process of diffusion controlled adsorption during the period between pulses. For this reason, a rigorous model is presented that describes the transformation of responses under the influence of reactant bulk concentration if the adsorption follows Langmuir isotherm. Limiting currents

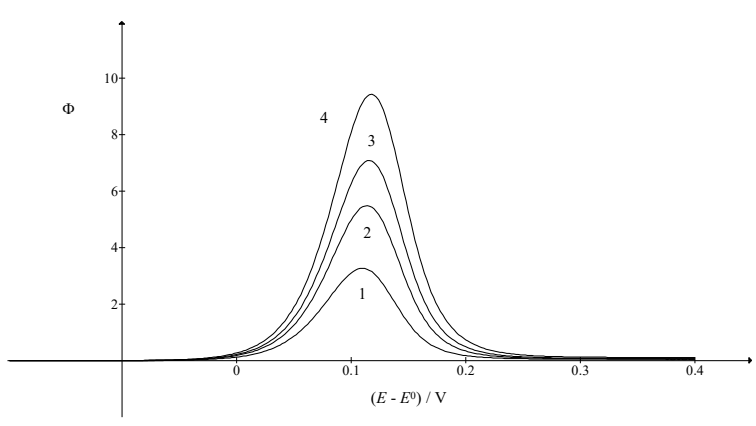

Figure 10. Dependence of normal pulse voltammograms on the duration of the period between pulses; $t_{p}=0.050 \mathrm{~s}$ and $t_{1} / s=0.150$ (1), 0.350 (2), 0.550 (3) and 0.950 (4). All other data are as in Figure 9.

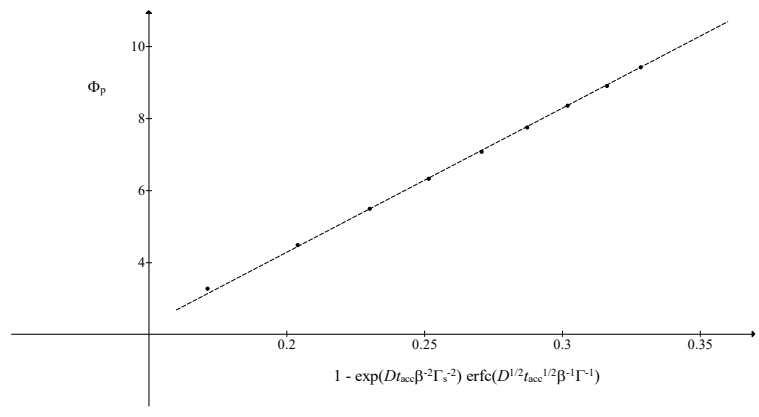

Figure 11. Relationship between the dimensionless peak current in normal pulse voltammetry and the function of the parameter $\left(D t_{\mathrm{acc}}\right)^{1 / 2} / \beta \Gamma_{\mathrm{s}}$. All data are as in Figure 10.

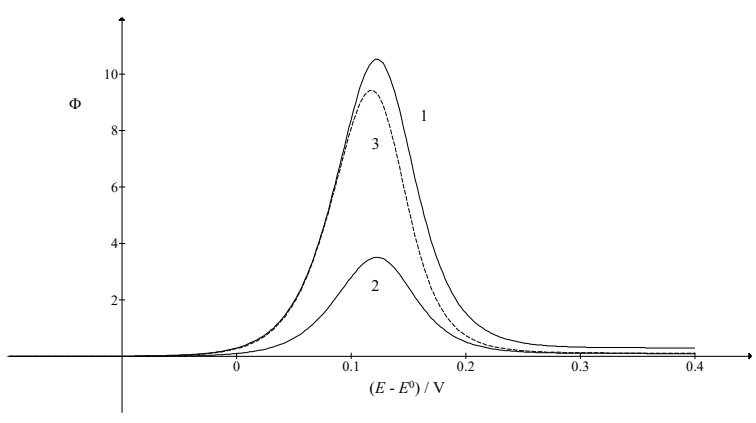

Figure 12. Influence of the initial reactant concentration on chronoamperograms. $D=10^{-5} \mathrm{~cm}^{2} \mathrm{~s}^{-1}, \beta \Gamma_{\mathrm{s}}=0.1 \mathrm{~cm}, t_{\mathrm{p}}=$ $0.050 \mathrm{~s}$ and $c_{\mathrm{A}, \text { ini }} / c_{\mathrm{A}}{ }^{*}=0.3$ (1) and 0.1 (2). The curve (3) is normal pulse voltammogram; $c_{A} * / \Gamma_{\mathrm{s}}=0.01 \mathrm{~cm}^{-1}, \beta \Gamma_{\mathrm{s}}=$ $0.1 \mathrm{~cm}, t_{1}=0.95 \mathrm{~s}, t_{\mathrm{p}}=0.05 \mathrm{~s}$ and $D=10^{-5} \mathrm{~cm}^{2} \mathrm{~s}^{-1}$. 
in both normal pulse voltammetry and chronoamperometry are not influenced by the electro-oxidation of adsorbate, but depend on the electrode reaction of dissolved reactant and its diffusion from the bulk of solution.

\section{REFERENCES}

[1] J. Osteryoung, K. Hasebe, Rev. Polarog. 1976, 22, 1.

[2] J. G. Osteryoung, M. M. Schreiner, CRC Crit. Rev. Anal. Chem. 1988, 19, S1.

[3] S. Sujaritvanichpong, K. Aoki, K. Tokuda, H. Matsuda, J. Electroanal. Chem. 1986, 199, 271.

[4] K. Wikiel, M. M. dos Santos, J. Osteryoung, Electrochim. Acta 1993, 38, 1555.

[5] D. Jadreško, M. Zelić, J. Electroanal. Chem. 2013, 707, 20.

[6] E. Laborda, J. Gonzalez, A. Molina, Electrochem. Commun. 2014, 43, 25.

[7] J. B. Flanagan, K. Takahashi, F. C. Anson, J. Electroanal. Chem. 1977, 85, 257.

[8] M. Lovrić, J. Electroanal. Chem. 1984, 170, 143.

[9] H. P. van Leeuwen, J. Electroanal. Chem. 1982, 133, 201.

[10] K. Holub, H. P. van Leeuwen, J. Electroanal. Chem. 1984, 162, 55.

[11] H. P. van Leeuwen, J. Electroanal. Chem. 1984, 162, 67.

[12] F. Mas, J. Puy, F. Sanz, J. Virgili, J. Electroanal. Chem. 1985, 183, 73.

[13] K. Holub, H. P. van Leeuwen, J. Electroanal. Chem. 1985, 191, 281.

[14] H. P. van Leeuwen, M. Sluyters-Rehbach, K. Holub,
J. Electroanal. Chem. 1985, 191, 293

[15] J. Galvez, S. M. Park, J. Electroanal. Chem. 1989, 263, 269.

[16] N. Fatouros, D. Krulic, J. Electroanal. Chem. 1999, 478, 25.

[17] H. P. van Leeuwen, J. Buffle, M. Lovrić, Pure Appl. Chem. 1992, 64, 1015.

[18] M. Lovrić, M. Zelić, Š. Komorsky-Lovrić, Collect. Czech. Chem. Commun. 2001, 66, 423.

[19] M. Lovrić, M. Zelić, J. Electroanal. Chem. 1991, 316, 315.

[20] F. Mas, J. Puy, J. M. Diaz-Cruz, M. Esteban, E. Casassas, J. Electroanal. Chem. 1992, 326, 299.

[21] J. Puy, F. Mas, J. M. Diaz-Cruz, M. Esteban, E. Casassas, J. Electroanal. Chem. 1992, 328, 271.

[22] J. Puy, F. Mas, J. M. Diaz-Cruz, M. Esteban, E. Casassas, Anal. Chim. Acta 1992, 268, 261.

[23] F. Mas, J. Puy, J. M. Diaz-Cruz, M. Esteban, E. Casassas, Anal. Chim. Acta 1993, 273, 297.

[24] J. Galceran, J. Salvador, J. Puy, J. Cecilia, M. Esteban, F. Mas, Anal. Chim. Acta 1995, 305, 273.

[25] A. A. Barros, J. A. Rodrigues, Portugaliae Electrochim. Acta 1996, 14, 233.

[26] A. M. Garrigosa, J. M. Diaz-Cruz, C. Arino, M. Esteban, Electrochim. Acta 2008, 53, 5579.

[27] D. Britz, J. Strutwolf, Digital Simulation in Electrochemistry, Springer, Berlin, Germany, 2016.

[28] Š. Komorsky-Lovrić in Electroanalytical Methods, (Ed. F. Scholz), Springer, Berlin, Germany, 2010, p. 273.

[29] P. Delahay, I. Trachtenberg, J. Am. Chem. Soc. 1957, 79, 2355. 